\title{
Os estranhamentos entre aqueles que estavam aqueles que chegam: representações sobre o espaço e as relações entre indígenas e imigrantes alemães no rio Grande do Sul, Brasil
}

The estrangement between those who were and those arriving: representations of space and the relationship between indigenous and German immigrants in Rio Grande do Sul, Brazil

\author{
Daniel Luciano Gevehr* \\ danielgevehr@hotmail.com \\ Gabriela Dilly** \\ gabidilly@hotmail.com
}

\begin{abstract}
Resumo: A pesquisa analisa as representações sobre o espaço natural e sobre a relação existente entre os nativos e os colonizadores da área de colonização alemã no Rio Grande do Sul, construídas em diferentes épocas e contextos, pelo intelectual e político Karl Von Koseritz, pelo jesuíta Ambrósio Schupp e pelo monsenhor Matias José Gansweidt. Privilegiamos em nossa pesquisa os escritos produzidos por Koseritz e Schupp no final do século XIX, colocando os Mucker como exemplo dos colonizadores que foram seduzidos pela natureza selvagem e, com isso, comparados aos nativos que habitavam a região. Num segundo momento, aproximamos nossa análise sobre os escritos de Matias José Gansweidt, que na década de 1940, produziu suas narrativas sobre os ataques dos nativos nas áreas ocupadas pelos imigrantes alemães no Rio Grande do Sul. Discutimos quais os elementos simbólicos presentes nessas narrativas e, em que medida, estas podem ser entendidas como responsáveis, em grande parte, pela difusão de representações negativas sobre os nativos e suas relações com os imigrantes alemães, na passagem do século XIX para o século XX.
\end{abstract}

Palavras-chave: imigração alemã, representações, relações interétnicas

Abstract: The research analyzes the representations of the natural space and the relationship between the natives and the Colonists from the German settlement area in Rio Grande do Sul, built at different times and by the contexts, the intellectual and political Karl Koseritz and Jesuit Ambrose Schupp and by Monsignor José Matias Gansweidt. We focused our research on the writings produced by Koseritz and Schupp in the late nineteenth century, putting the Mucker movement as an example of the settlers who were seduced by the wild nature and, therefore, compared to the natives who inhabited the region. Secondly, our analysis approaches the writings of Matias Jose Gansweidt who in the 1940s, produced his narratives about the raids by the natives in the areas occupied by German immigrants in Rio Grande do Sul. We discussed which symbolic elements are presente in these narratives and, to what extent these can be seen as responsible, largely, for the spread of negative representations of the natives and their relations with German immigrants in the late nineteenth century to the twentieth century.

Keywords: german immigration, representations, interethnic relations

\footnotetext{
*Doutor em história e professor do Programa de Pós-Graduação em Desenvolvimento Regional da FACCAT.
}

**Graduada em história e mestre pelo Programa de Pós-Graduação em Desenvolvimento Regional da FACCAT. 


\section{Considerações iniciais}

A escrita da história da imigração alemã no sul do Brasil tem revelado, na última década, novos problemas de pesquisa, que por sua vez, permitem um diálogo cada vez mais amplo e interdisciplinar com outras áreas do conhecimento. As novas abordagens têm revelado um campo bastante rico e diversificado, no qual os escritos sobre a história da imigração contemplam novas questões, até então negligenciadas pela historiografia.

Nessa perspectiva, pretendemos estudar a imigração alemã no Rio Grande do Sul, procurando desvendar os caminhos percorridos por parte de sua produção historiográfica, buscando compreender o texto dentro do contexto de sua produção (CARDOSO, 2012) e os mecanismos envolvidos na produção e difusão de representações sobre espaços e personagens envolvidos nesse processo. Esse nos parece ser um caminho cada vez mais possível e necessário, para que novas interpretações sobre a produção de uma memória da imigração (DREHER, 2014) se torne um exercício cada vez mais amplo e multidisciplinar.

Tendo essa questão como ponto de partida, procuraremos analisar as representações construídas sobre o espaço natural e sobre a relação existente entre os nativos e os imigrantes da área de colonização alemã no Rio Grande do Sul, construídas em diferentes épocas e contextos, por Karl Von Koseritz, Ambrósio Schupp, e por Matias José Gansweidt. As narrativas produzidas por eles nos permitem pensar sobre as circunstâncias em que são produzidas representações sobre o processo imigratório no sul do Brasil e sobre os condicionantes envolvidos na consolidação de determinadas "verdades" sobre os diferentes espaços e personagens inscritos nesse processo.

Ao desvendar o processo que envolve a manipulação da memória da imigração alemã no sul do Brasil, procuramos contribuir para o exercício crítico da história e também como uma possibilidade de (re)escrita do passado da imigração alemã, que possa romper com determinadas perspectivas historiográficas de valorização de um discurso étnico (SEYFERTH, 2012), mas sim em favor da valorização da diferença cultural presente no contexto da imigração no sul do Brasil. ${ }^{1}$

Num primeiro momento, privilegiamos a análise dos escritos produzidos por Koseritz - intelectual e político atuante do final do século XIX - e Schupp - jesuíta alemão - no final do século XIX, que procuram construir uma representação sobre os imigrantes alemães a partir da negação dos Mucker $^{2}$. Ou seja, para os dois autores, os Mucker não poderiam ser identificados como exemplo do Deutschtum - a germanidade (SEYFERTH, 2011), ou seja, da identidade étnica dos alemães. Isso se explicava em razão dos Mucker não serem considerados seguidores da verdadeira germani$d a d e^{3}$. Para os autores, os Mucker foram seduzidos pela natureza selvagem e, com isso, poderiam ser compara-

\footnotetext{
${ }^{1}$ Acreditamos, todavia, que há grandes diversidades mesmo dentro do grupo de imigrantes alemães, que são muitas vezes esquecidas pela historiografia.

${ }^{2} \mathrm{O}$ conflito ocorreu na Antiga Colônia Alemã de São Leopoldo e envolveu um grupo de aproximadamente 600 colonos de origem alemã. O grupo foi liderado por Jacobina Mentz Maurer, que lia e interpretava a Bíblia em uma espécie de culto doméstico em sua casa, no morro Ferrabraz. Além disso, seu marido, João Jorge Maurer praticava o curandeirismo, através da utilização de plantas medicinais. O conflito acabou em 1874, com a ação das forças imperiais, lideradas pelo Coronel Genuíno Sampaio, que morreu em combate. O termo Mucker tem diversos significados, como santarrão, fanático religioso, embusteiro, entre outros e foi utilizado para imprimir um caráter negativo para o grupo do Ferrabraz. Além disso, poderíamos pensar na associação existente entre o movimento Mucker do Ferrabrás e os Movimentos Mucker ocorridos, por exemplo, em Königsberg na Antiga Prússia durante o século XIX. Podemos, também pensar, neste mesmo contexto, no caldo cultural-religioso que possa ter influenciado o movimento Mucker; Pietismo, antisecularismo, curandeirismo na Alemanha - uma vez que a antiga Pomerania detinha uma tradição muito forte de curandeirismo, etc.

${ }^{3}$ A ideia de Germanidade, advogada pelos autores que serviram de fonte para o autor/autora vem sofrendo recentemente novas interpretações. A partir, principalmente do trabalho de Frederik Schulze, em Auswanderung als nationalistisches Projekt: Deutschtum und Kolonialdiskurse im Südlichen Brasilien (1824-1941) percebe-se que o discurso de Germanidade foi também mediado por atores "menores" e subalternos. Cabe lembrar que o discurso de Germanidade proferido por Koseritz, Gansweidt e Schupp era também negociado por outros grupos. Os intelectuais e membros da Igreja advogavam um tipo de Deutschtum, mas a população teuto-brasileira - geralmente - não ficou imune a essa discussão.
} 
dos aos nativos - os indígenas - que habitavam a região antes de sua chegada.

Já num segundo momento, aproximamos nossa análise com os escritos do padre Matias José Gansweidt - representante da fé na região colonial alemã - que na década de 1940, produziu suas narrativas ${ }^{4}$ sobre os ataques dos nativos nas áreas ocupadas pelos imigrantes alemães no Rio Grande do Sul. Buscamos discutir quais os elementos simbólicos presentes nessas narrativas e, em que medida, estas podem ser entendidas como responsáveis, em grande parte, pela difusão de representações negativas sobre os nativos e as relações interétnicas (POUTIGNAT; STREITFF-FENART, 1998) estabelecidas com os imigrantes alemães.

A pesquisa considera essas narrativas, como uma importante fonte para a análise e para a ampliação dos estudos culturais, no âmbito da história da imigração no sul do Brasil. Isso se explica, na medida em que nos propomos a estabelecer aproximações entre as representações difundidas pelos autores, detentores de um poder simbólico e dotados, portanto, de legitimidade, em seus discursos - uma vez que se colocam na posição de homens da ciência, como no caso de Koseritz, ou da fé, como no caso de Schupp e Gansweidt. Esses, por sua vez, se apresentaram como portadores de veracidade e que procuraram, ainda, imprimir uma determinada identidade sobre o espaço natural, os nativos e os imigrantes alemães, até a primeira metade do século XX.

Conforme veremos, a paisagem colonial e seus moradores tomarão uma dimensão singular - como na perspectiva da micro-história (LIMA, 2012) - nas representações difundidas pelos autores. Ainda que inseridos em contextos e épocas distintas - o final do século
XIX e a década de 1940 respectivamente - iremos perceber muitas semelhanças e aproximações nas representações difundidas pelos três autores através de suas narrativas.

Tanto Koseritz, que difundia suas ideias através do jornal, quanto Schupp e Gansweidt, que acabaram se tornando referências para a historiografia sobre a imigração alemã, contribuíram decisivamente para a produção de uma memória (HALBWACHS, 2004) da imigração alemã no sul do Brasil, que procurou vitimizar os imigrantes alemães, frente à natureza selvagem $e$ hostil, habitada pelos indígenas Essas narrativas, acabaram influenciando decisivamente a difusão de uma memória e uma identidade (CANDAU, 2012) sobre o processo de desenvolvimento dos imigrantes no Rio Grande do Sul.

Nesse sentido, poderíamos pensar essa relação a partir do conceito de alter ego (HARTOG, 2014), que nos faz pensar que a identidade dos alemães se construiu, nesse contexto, através de um processo de contraposição/negação das representações construídas sobre os indígenas. Nesse caso, a identidade étnica dos alemães se constituía pela negação daquilo que era identificado como "indígena", que passa a ser desqualificado.

Exemplo dessa representação, temos na difusão de uma memória sobre o cenário do conflito Mucker. Local de moradia e de realização dos cultos de Jacobina e das práticas de curandeirismo de João Jorge Maurer, o morro Ferrabraz foi alvo de várias interpretações, que procuraram evidenciar o caráter misterioso e selvagem do lugar, como um dos motivos para a eclosão do conflito.

\footnotetext{
${ }^{4}$ A narrativa é compreendida na pesquisa enquanto um conjunto de ideias produzidas e difundidas pelos seus autores através de suas publicações. Nesse caso específico, as narrativas são portadoras de um significado que procura evidenciar elementos étnicos e encontram-se em um determinado contexto cultural de produção.
} 
Em nossa análise, consideramos que as representações sociais (CHARTIER, 2002) construídas sobre o morro Ferrabraz - entendido em nossa pesquisa como um símbolo que aponta para o caráter selvagem da região colonial - não se encontravam apenas em textos historiográficos, mas também em diferentes formas narrativas. As representações são, portanto, compreendidas em nossa pesquisa como as formas de apresentar/ expor/difundir determinadas ideias, buscando com isso influenciar os imaginários coletivos, que passam a compartilhar certas imagens e ideias sobre aquilo que é apresentado pelo autor.

Para Ferreira (2004) a caracterização e análise das formas e conteúdos presentes nas representações sociais podem ser realizadas a partir da investigação das mais variadas fontes. Entre elas, destaca a análise realizada a partir de textos historiográficos, os diversos tipos de discursos - jurídicos, médicos, filosóficos, teológicos - os textos literários e as pinturas, os museus, as narrativas cinematográficas, entre outras.

Isso nos faz pensar naquilo que Pollack (1989, p. 4) chamou de trabalho de constituição e de formalização das memórias. Segundo ele, para que nossa memória se beneficie da dos outros, não basta que ela nos traga apenas o testemunho, mas sim que esta encontre muitos pontos de convergência entre aquilo que queremos afirmar e as memórias de nossos testemunhos. Somente a partir do encontro dessas memórias é que podemos reconstruir as lembranças do passado sobre uma base comum. Em nossa investigação, procuramos compreender como os autores analisados procuraram respaldar seus discursos a partir desses testemunhos, que procuravam dar veracidade às suas narrativas.

As representações sociais construídas sobre o conflito permitem-nos ainda pensar no trabalho especializado de enquadramento (POLLACK, p. 11). Nesse caso, a memória é alvo de manipulações e defesa de interesses pessoais e coletivos, estando necessariamente relacionada com o contexto e com a época em que foi produzida.

Quanto a essa questão, observamos que as representações construídas sobre os imigrantes alemães e sobre os nativos do Rio Grande do Sul na passagem do século XIX para o século XX, inseriam-se precisamente nesse contexto, no qual a memória foi manipulada de forma que a imagem produzida foi enquadrada segundo os objetivos de cada autor e de acordo com sua época.

Podemos ainda analisar as representações ligadas àquilo que Seixas $(2004$, p. 53) descreveu como um conjunto de interesses coletivos, no qual lembramos menos para conhecer do que para agir. Segundo a autora, a memória está menos ligada ao entendimento do passado, mas sim diretamente identificada com os interesses que fazem as pessoas rememorarem um determinado fato. Assim, não existe uma memória desinteressada. Ao contrário, a memória teria um destino prático, realizando a síntese do passado e do presente visando ao futuro, buscando os momentos passados para deles se servir.

Relacionado com essa questão que envolve a memória coletiva e a construção das representações, devemos atentar para o estudo realizado por Bourdieu (2001), que nos mostra como a produção de discursos está diretamente ligada ao contexto no qual estes se fazem presentes. Inseridos no campo das relações de poder, os discursos procuram estabelecer uma determinada ordem das coisas, seguindo interesses de ordem política, econômica, social e cultural.

Bourdieu, por sua vez, nos mostra que a produção dos discursos não ocorre de forma inocente nem inconsciente, mas sim como resultado de interesses de determinados grupos, detentores de um poder simbólico. Segundo ele, esse poder age sobre as estruturas so- 
ciais, impondo uma determinada visão dos fatos, transformando-os em verdades absolutas.

Ainda em relação às representações e seu campo de produção, valemo-nos dos estudos realizados por Peter Burke (2004, p. 54-55), para quem uma paisagem - ou, neste caso, a sua descrição - evoca associações políticas ou até mesmo uma ideologia, como no caso da representação de uma identidade sobre os imigrantes alemães.

Analisando o espaço geográfico do sul do Brasil - habitado originalmente pelas populações indígenas e que, a partir do século XIX, será ocupado pelos imigrantes alemães - através da teoria proposta por Burke, pensamos a descrição do espaço, veiculado pela historiografia, como um símbolo da maior importância. Torna -se conveniente destacar o fato de que esse espaço foi também caracterizado como parte do mundo caboclo; da economia extrativista de erva-mate; da peonagem; dos açorianos; etc. Isso se deve, especialmente, ao fato de que os contatos com as sociedades caboclas foram de grande importância para as definições identitárias dos imigrantes europeus.

Atentamos ainda para o estudo realizado por Edgar de Decca (2004), que nos ajuda a compreender o papel desempenhado pela literatura, enquanto difusora de representações de Euclides da Cunha sobre o conflito de Canudos. Nela o autor destaca o papel desempenhado por Euclides da Cunha na difusão de imagens sobre o conflito de Canudos. Nesse sentido, a análise literária realizada por Decca contribuiu para nossa investigação, na medida em que nos forneceu subsídios para compreendermos as narrativas construídas pelos autores analisados em nosso estudo sobre o sul do Brasil.

Exemplo da difusão dessas representações será o morro Ferrabraz, no atual município de Sapiranga e onde, no final século XIX, ocorreu o conflito Mucker. Com sua geografia recortada, o morro Ferrabraz sugeria aos tropeiros de gado que por ali passavam, ainda no século XVIII, a imagem de um monstro sarraceno Fier$\grave{a}$-bras, que mais lembrava a imagem distante do gigante sarraceno que aparecia nas canções de gesta da Europa medieval. Atualmente, o morro é um dos cartões postais da cidade e atrai muitos turistas em função da prática do voo-livre, conferindo à cidade o título de capital do voo-livre.

Espaço físico e local das práticas de Jacobina e João Jorge Maurer e, ainda, de residência de muitos Mucker, o morro Ferrabraz pode ser interpretado como um importante símbolo identificado com o passado da imigração alemã.

Na primeira etapa de nossa pesquisa, concentramo-nos em analisar de forma mais aprofundada as representações difundidas sobre o cenário dos Mucker enquanto representação de uma natureza selvagem, que teria seduzido os imigrantes, para que em seguida possamos melhor compreender como Koseritz, Schupp e Gansweidt irão construir suas narrativas sobre os imigrantes e a influência dos indígenas sobre a formação das comunidades teuto-sul-rio-grandenses na passagem do século XIX para o século XX.

Ressaltamos que é impossível mensurar o alcance das narrativas entre o público leitor, uma vez que essas eram lidas por aqueles que eram alfabetizados na área de colonização alemã. Entretanto, acreditamos que suas ideias eram compartilhadas, também, entre aqueles que não sabiam ler, através das rodas de conversa, entre vizinhos ou até mesmo entre as famílias. Dessa forma, tanto as narrativas veiculadas por Koseritz na imprensa, quanto por Schupp e Gansweidt através de suas obras, atingiam um público muito maior que seus leitores. 
Koseritz e Schupp diante da natureza selvagem: os alemães entre a razão e a fé

Iniciamos nossa discussão sobre o papel desempenhado por Koseritz e Schupp, com a tese defendida por Dickie, para quem a representação dos Mucker como fanáticos, ocorreu especialmente por esses não serem considerados pelos intelectuais da época como portadores e defensores da cultura alemã. Neste caso, a cultura alemã estaria especialmente associada aos valores como família, convívio em sociedade, participação nos cultos e missas das Igrejas, bem como a valorização do trabalho, elemento essencial em suas vidas.

A desclassificação - e falta de erudição dos Mucker - se afirma, na medida em que esses passam a ser representados como sujeitos rudes, cujas qualidades não se assemelham àquelas dos demais moradores da Colônia que continuam frequentando as festas, os cultos e missas, e todas as outras atividades sociais. A autora destaca a edição publicada em 17 de maio de 1873 do Deutsche Zeitung, na qual Koseritz aponta para a desqualificação dos Mucker, apresentando-os como “não alemães", sendo que:

A desqualificação tinha duas matrizes que reiteraram a retórica de Koseritz: por um lado, a racionalistal evolucionista, pela qual mucker é sinônimo de "natureza não civilizada", "selvageria", "falta de esclarecimento" e "embuste religioso"; por outro, a matriz étnica, através da qual efetuou a exclusão pública dos mucker, ao equiparar as atividades de Maurer às de um "indio velho" e às da feitiçaria africana, chamando-o de "negro branco". Maurer era, portanto, um não alemão (DICKIE, 1996, p. 317).

O caráter depreciativo com que a imprensa do final do século XIX referia-se aos Mucker torna clara a intenção de tentar imprimir na população uma determinada visão acerca desse grupo, representando-os de forma bastante parcial. Os artigos veiculados pela imprensa permitem-nos observar como não havia preocupação em esclarecer os condicionantes envolvidos no conflito Mucker. Em relação a essa questão, Dickie afirma que:

\begin{abstract}
Os mucker personificavam um inimigo muito poderoso, na retórica da cidadania étnica por que definiram uma gramática de existência alicerçada sobre valores que Koseritz não podia reconhecer como pertencendo à comunidade étnica. Os Mucker eram a antitese da ideia que faziam dos colonos como elementos realizadores do futuro que ele almejava para aquela comunidade, o futuro de realizações da cidadania brasileira reservado à "civilizada e religiosa raça ale$m \tilde{a}$ ” (1996, p. 322-323).
\end{abstract}

A antítese mencionada pela autora revela que os Mucker representavam, acima de tudo, um perigo para a continuidade do desenvolvimento da região colonial alemã, uma ameaça tanto para sua segurança quanto para sua integridade religiosa. Os alemães civilizados, isto é, os não Mucker, representavam, assim, o seu oposto, pois, como referido no discurso de Koseritz, seriam os responsáveis pela prosperidade econômica, social, política e religiosa da colônia.

Dickie constatou que se construiu uma determinada representação social, um rótulo que inseriu os Mucker no imaginário coletivo como o não civilizado, como aquele que, ao ocupar o banco dos réus, foi também alvo de condenação moral. Dessa forma, esse grupo não poderia ter sua identidade (WOODWAR, 2014) - pela diferença - associada à dos demais imigrantes alemães, mas sim a representação que se tinha dos nativos que habitavam a região antes da chegada dos imigrantes. Nesse sentido, os Mucker poderiam ser comparados aos indígenas - cuja representação negativa era bastante evidente nessa época - mas não aos demais imigrantes alemães que se instalavam no sul do Brasil.

Consideramos fundamental o estudo realizado por Moacyr Domingues (1977), que após exaustivo levantamento documental e bibliográfico, publicou sua obra na qual apresentou não só os principais aspectos 
do conflito, mas também desvendou as origens familiares dos principais envolvidos no conflito. Para tanto, valeu-se, em vários momentos, das versões apresentadas por Karl Von Koseritz. ${ }^{5}$

Encontramos, logo nas primeiras páginas da obra, uma descrição do Ferrabraz à época dos acontecimentos. Para fazê-lo, Domingues valeu-se da descrição feita por Koseritz e publicada no jornal Rio Grandense do ano de 1874. Ao convidar o leitor para que brindemos com uma página de Carlos Von Koseritz, jornalista brilhante e prosador inspirado, Domingues posiciona-se favoravelmente à versão de Koseritz.

A imagem construída do Ferrabraz por Koseritz e apresentada por Domingues ressalta o caráter depreciativo e até polêmico com que descreveu o cenário do conflito. Seu texto intitulado $O$ palco da tragédia procura informar o leitor sobre o local, descrito como uma "região de incrível uberdade, mas montanhosa e ainda coberta de espessas matas, cujas árvores seculares servem de abrigo a animais ferozes, e são ainda, não raras vezes, visitadas por errantes tribos de indigenas" (VON KOSERITZ, p. 24).

Embora Koseritz tenha chegado a afirmar que a paisagem da região era das mais lindas e pacíficas, habitada por um alegre e bem disposto povo - leia-se de origem alemã - não deixa de enfatizar a selvageria que faz lembrar também dos nativos - inerente do lugar. A paisagem do Ferrabraz causava medo nas pessoas (VON KOSERITZ, p. 24-25), por sua altitude e ve- getação densa, e também por seu estado de selvageria e de incivilização, ao ser habitado por animais ferozes e por indígenas. Segundo sua interpretação, a própria geografia acidentada do Ferrabraz havia propiciado o surgimento de um grupo de revoltosos, já que a densa floresta servia muitas vezes de esconderijo.

\section{A Fraude Mucker na Colônia Alemã. Uma Con-} tribuição para a história da cultura da germanidade daqui, de 1875, apresenta a primeira imagem idealizada de Jacobina, que passa a representar a imagem da $m u$ lher não-alemã. Publicado por Koseritz em seu Koseritz Kalender (1875) o artigo procurava alertar as pessoas para os fatos que ocorriam, consistindo num "ato de denúncia" em relação ao grupo que se organizava no Ferrabraz. Para Koseritz (1875, p. 1) o movimento não se enquadrava na realidade da colônia alemã de São Leopoldo, o que justificava a denúncia de que "estes fatos lançam luz terrível sobre nosso progresso e que são motivo das mais sérias preocupações para o futuro". Apresentando os Mucker como fanáticos religiosos e avessos aos avanços da ciência, Koseritz tece críticas severas a eles, na medida em que não praticavam os valores da verdadeira germanidade. ${ }^{6}$

O alvo preferido por Koseritz foi Jacobina, que segundo ele representava a demência religiosa que havia se instaurado na colônia, devido à indigestão crônica de passagens bíblicas, aliada ao temor cuidadosamente nutrido ante o inferno e o diabo. No artigo de Koseritz, Jacobina desempenhava o papel de guia espi-

\footnotetext{
${ }^{5}$ Karl Von Koseritz nasceu em 03 de fevereiro de 1834, em Dessau, na Alemanha. Lutou na revolução de 1848 na Alemanha ao lado das forças liberais contra os reacionários defensores do conservadorismo monárquico decadente. Chegou pela primeira vez ao Brasil em 1850, regressando logo em seguida à Alemanha. Chega pela segunda vez ao Brasil e acaba participando do grupo formado para lutar contra Rosas na Argentina, conhecido como os Brummer. Antes mesmo de começar o combate acaba desistindo da atividade, passando a desempenhar várias atividades profissionais. Em 1855 casouse com Zeferina Maria de Vasconcelos, filha de um rico fazendeiro da Campanha. Karl Von Koseritz teve grande atuação no cenário político do Rio Grande do Sul da segunda metade do século XIX, em especial ao lado dos liberais. Num primeiro momento, Koseritz trabalhou como jornalista em Pelotas e Rio Grande, sendo que em 1864 assumia a direção do Deutsche Zeitung, de Porto Alegre. Concomitante a essa função, escrevia artigos para $O$ Mercantil, O Jornal do Comércio, A Reforma, O Rio Grandense e a Gazeta de Porto Alegre. Além disso, Koseritz teve grande participação na política do Rio Grande do Sul, ao lado dos liberais, onde desempenhou forte atuação na defesa dos interesses do partido. Faleceu em 1890.

${ }^{6}$ Lembramos que esta publicação ocorreu em meio às comemorações do $50^{\circ}$ Jubileu da Cidade de São Leopoldo, que, segundo Koseritz, eram alusivas à coragem alemã e pelo trabalho alemão. Ainda como exemplo da exaltação da germanidade, Koseritz refere-se aos imigrantes e seus descendentes como portadores do cerne operoso da natureza alemã e de natureza sadia da raça alemã.
} 
ritual e acorrentava as pessoas através da leitura e interpretação da Bíblia. Na versão publicada em 1880, sob o título Marpingem ${ }^{7}$ und der Ferrabraz, Jacobina é descrita como mensageira da palavra de Cristo. Para o autor, contudo, Jacobina não passava de uma enganadora, que se dizia proferir palavras divinas aos seus adeptos do Ferrabraz. A atitude de Jacobina foi associada ao ambiente rude e hostil - de pouca formação intelectual - e à ausência de amparo científico, que a privavam do conhecimento mínimo das leis que regem o universo.

Assim como Jacobina, João Jorge Maurer também foi alvo de críticas severas, tendo sido identificado como responsável pelos atos cometidos pelos Mucker. Koseritz comparou a ação de curandeiro de Maurer a outras tantas existentes na história mundial, interpretando-a como produto da ignorância. Para ele, Maurer era a representação do homem não-alemão, seduzido pela natureza selvagem.

Vale lembrar que na década de 1870, havia vários aspectos presentes no Rio Grande do Sul que apontavam para a preocupação, tanto por parte dos políticos quanto dos intelectuais, em relação ao progresso - e a ideia de contraposição àquilo que é considerado incivilizado, rústico e desprovido de cientificidade.

Exemplo disso era Carlos Von Koseritz, que representava o pensamento de Charles Darwin, o materialismo e diversas correntes progressistas. Também atentamos para a ideia de ordem e progresso, que aparece a partir de 1889, com frequência nas narrativas sobre o movimento e seu desfecho. Esse lema ganhou expressão a partir de 1889, quando se deu a instalação do governo republicano, que tinha como principio filosófico o positivismo (SILVA, 2013), cujos desdobramentos podem ser claramente percebidos na historiografia so- bre a imigração, já no final do século XIX no Rio Grande do Sul.

Cabe também destacar que havia, no âmbito das colônias alemãs no sul do Brasil, um clima de animosidade entre católicos e protestantes - ainda que por vezes havia interessantes simbioses entre esses grupos. As disputas estabelecidas entre esses dois grupos podem ser observadas através da imprensa do final do século XIX, na qual "Imbuídos do espírito do Kulturkampf, somado ao fanatismo maçônico, havia, aqui, nãocatólicos, que manejavam com habilidade, a pena e buscavam difundir suas ideias. Dentre esses sobressaem Karl Von Koseritz [...]" (BOHNEN; ULLMANN, 1989, p. 149). Esse trecho demonstra, ainda que de forma pontual, o clima de tensão existente entre o grupo dos católicos - do qual o jesuíta Ambrósio Schupp fazia parte - e o dos não-católicos - do qual Koseritz fazia parte.

Em outro momento, os autores afirmam que o próprio jesuíta reconhecia a existência de um clima bastante tenso na Colônia, que segundo Schupp poderia, inclusive, fazer ressurgir o conflito Mucker, tal era a intolerância entre os católicos e protestantes (Ibidem, p. 156). Embora, situados em campos divergentes, ambos concordavam sobre as circunstâncias presentes no conflito Mucker e desempenharam papel preponderante no sentido de construir a representação dos Mucker como não-alemães e resultado do espaço não civilizado da Colônia Alemã.

Como nos mostra Seyferth (2012, p. 14), a imigração na Colônia Alemã de São Leopoldo "prosseguiu ao longo do século XIX e nas primeiras décadas do século XX, conformando paisagens culturais criadas por colonos estrangeiros e seus descendentes, de acordo com o princípio da diferença".

\footnotetext{
${ }^{7}$ Marpingen é traduzido por Leopoldo Petry como sendo um lugarejo da Alemanha.
} 
Lembramos que no contexto das décadas de 1870 e 1880 - em que temos a difusão das ideias de Koseritz - encontramos também a publicação da obra Os Muckers, do padre jesuíta Ambrósio Schupp ${ }^{8}$. Sua obra contribuiu de forma decisiva para a construção das narrativas sobre o conflito Mucker.

Destacamos a atuação do jesuíta na coleta de importantes informações sobre os acontecimentos que envolveram os Mucker e os demais moradores da colônia. Esse trabalho de pesquisa de campo realizado por Schupp ocorreu logo após o desfecho do conflito, ainda no ano de 1874. Schupp procurou ouvir os moradores da região que estiveram envolvidos de forma direta no combate aos Mucker, com a finalidade de publicar uma obra $^{9}$ que contasse a história do conflito e que, ao mesmo tempo, servisse de registro histórico dos depoimentos de seus sobreviventes. Cabe considerar que Schupp ouviu apenas os sobreviventes que se opuseram aos Mucker, ou seja, em sua narrativa, sobressaem as versões contadas pelos inimigos dos Mucker.

No momento em que anuncia como fontes de seu estudo os depoimentos de sobreviventes do conflito - 19 sobreviventes no total - o autor demonstra parcialidade em suas narrativas, uma vez que essas se constituem em narrativas que apontam para a desqualificação dos Mucker. Em nenhum momento de sua obra encontramos depoimentos de sobreviventes ligados ao grupo de Jacobina. Uma análise mais atenta de sua obra revelou-nos importantes aspectos que apontaram para a intenção de inocentar os demais imigrantes alemães que habitavam a região, apresentados por Schupp como víti- mas dos Mucker. Considerando que Schupp gozava de prestígio no contexto local, especialmente pela sua atuação religiosa e formação intelectual, o autor colocavase como alguém autorizado a falar em nome da comunidade, embora para isso buscasse a autorização através das assinaturas dos seus depoentes.

A descrição física do Ferrabraz como um lugar de "fronte carrancuda, mal-assombrado e coberta por escuro mato" (SCHUPP, s/d, p. 36) remetia o leitor a uma interpretação única em relação ao local. Com essas características pouco atrativas, devemos pensar na recepção desse texto, por parte dos leitores de sua obra, que receberam informações sobre o cenário do conflito e, em especial, sobre seus moradores.

Descrito como uma região de vegetação densa e de difícil acesso, a cidadella dos Mucker representava a resistência aos valores defendidos pelos demais moradores de origem germânica da localidade. Foi nesse ambiente de mistério descrito por Schupp (s/d, p. 42) que o "casal misterioso do Ferrabrás se deixou penetrar e possuir dessa convicção", aliando cura de doenças à prática religiosa. De acordo com Schupp, o Ferrabraz era um local caracterizado por uma vegetação densa, que facilmente poderia encobrir as práticas de Jacobina e João Jorge Maurer, ao mesmo tempo em que dificultava a chegada de pessoas de fora, em especial das autoridades e inimigos, que poderiam ser facilmente avistados pelos Mucker, quando se aproximavam do local onde ficava a fortaleza.

Como no exemplo do capítulo intitulado Entre Ferro e Fogo, Schupp (s/d, p. 201) procurou descrever

\footnotetext{
${ }^{8}$ Ambrósio Schupp nasceu em Montabaur, Alemanha em 26 de maio de 1840. Cursou filosofia e teologia na Universidade de Würzburg. Chegou ao Brasil em 10 de outubro de 1874, um pouco após o término do conflito Mucker. Nos primeiros 16 anos no Brasil, exerceu o cargo de Prefeito de Estudos no Colégio Nossa Senhora da Conceição, em São Leopoldo. Concomitante a essa função, exerceu o cargo de padre nas capelas de São Leopoldo, Hamburgerberg, Lomba Grande, Sapiranga e Mundo Novo. Em 1901, assumiu a direção do Seminário Episcopal e, em 1904, transferiu-se para Rio Grande, para dirigir o colégio da ordem jesuíta daquela cidade. Após essas atividades, finalmente atuou como professor no Ginásio São Luís, em Pelotas, vindo a falecer em 1914.

${ }^{9}$ Sua obra foi publicada primeiramente em 1900, em língua alemã, em Paderborn, na Alemanha. A tradução para o português e a consequente publicação no Brasil ocorreu apenas em 1906, pela editora Selbach \& Mayer, de Porto Alegre. A tradução para a língua portuguesa foi realizada por Alfredo Clemente Pinto.
} 
as ações dos Mucker, ressaltando seus objetivos fanatizados e referindo-se aos instintos perversos dos canibais, numa clara associação feita aos envolvidos. Chamamos a atenção para o fato de Schupp frequentemente referir-se aos seus entrevistados, chamando-os de testemunhas presenciais. Esse parece ser um aspecto importante em nossa investigação, uma vez que Schupp tornou-se o porta-voz dos testemunhos de seus entrevistados.

Agregaram-se às percepções anteriores as referências à festa de sangue (SCHUPP, p. 216) e à orgia de sangue nas picadas (s/d, p. 221) as quais Jacobina estaria promovendo no Ferrabraz. Nesse momento, o Ferrabraz passou a ser qualificado como espaço marcado pelo medo e pela morte, que teria se espalhado entre os moradores.

De forma semelhante a Koseritz, Schupp apresentou Jacobina como a principal responsável pelos acontecimentos do Ferrabraz que, segundo ele, teriam resultado do desamparo e da ignorância dos moradores da localidade. Nesse contexto de dificuldades, Jacobina desempenhou seu papel de líder religiosa, ao presidir cultos e ao ditar regras de convívio do grupo. Procurou também apresentar Jacobina como uma pessoa dotada de capacidades limitadas e praticante de atos criminosos.

Schupp manteve a versão detratora iniciada com os artigos de Koseritz, ao ressaltar que Jacobina, ao final do conflito, teria sido descoberta ao lado de seu suposto amante. Na descrição de uma Jacobina totalmente fora de si, percebe-se a intenção do autor de "explorar" o horror e o medo dos leitores. Para ele, a população, outrora tão pacífica e sensata, estava sob a ameaça dos desatinos praticados por Jacobina, que teria aguçado seus sentimentos, provocando a reação dos colonos que, imediatamente, perceberam o ridículo do conciliábulo fanático do Ferrabrás (VON KOSERITZ, p.75).

\section{As vítimas do bugre: a narrativa, a saga, o fantástico}

A fim de introduzir o leitor a uma das obras que aqui serão analisadas, será apresentada breve síntese do conteúdo e do contexto do livro "As vítimas do bugre Peripécias de prisioneiros brancos entre índios e descrição dos costumes dêstes.", escrito pelo Monsenhor Matias José Gansweidt. A obra possui texto original em alemão, publicado em 1929 e posterior tradução para a língua portuguesa no ano de 1946 (feita pelo Irmão Eugênio Damião), com edição da Livraria Selbach, de Porto Alegre.

A história narrada teria acontecido no ano de 1867 e é apresentada como uma narrativa "real" dos fatos ocorridos, os quais o autor teria tido conhecimento a partir do testemunho do sobrevivente que vivenciou a mesma. Tanto se pressupõe como verdadeira que utiliza-se de meios oficiais para comprovar isso: logo nas primeiras páginas encontramos uma declaração de Jacó Versteg, afirmando que a história "corresponde a realidade", estando esta declaração registrada em cartório. "Há uma clara necessidade de confirmação daqueles que seriam os donos da memória sobre os eventos narrados no livro do religioso." (DORNELLES, 2011, p. 247).

A narrativa inicia com um breve contexto sobre a imigração alemã e as dificuldades dos primeiros anos, referindo-se ao desconhecimento do imigrante sobre o Rio Grande do Sul, os ataques de indígenas, a língua, entre outros. Depois explica quem é Luis Bugre, personagem presente já no título. Gansweidt explica que Luis era um indígena por sua origem, que aos 11 anos foi atingido em uma represália de imigrantes a um ataque de índios (provavelmente Coroados) ocorrido em 1847 na propriedade de Jacó Bohn, na atual cidade de Feliz. Esse nativo acabou por continuar vivendo entre os imigrantes, como prisioneiro. Como nenhuma famí- 
lia alemã quis ficar com ele, agregou-se a Matias Rodrigues da Fonseca, português integrado à colônia. $\mathrm{O}$ menino foi batizado dois anos depois como Luís Antônio da Silva Lima. Cresceu em liberdade gostando de enveredar-se nas matas da região que conhecia como ninguém, desempenhando sempre o papel de guia toda vez que se fazia necessária a entrada vegetação adentro. Passou a vida circulando entre o grupo de imigrantes e de indígenas, vivenciando as duas culturas de forma intensa. Utilizava-se desse seu livre acesso para negociar entre os grupos, "[...] estabelecendo trocas comerciais de produtos como mel, peles, aves, espelhos, facas de metal, açúcar, sal.” (DORNELLES, 2011, p. 252)

Sobre Luis Bugre, Gansweidt relata:

Vagueia pela floresta ou visita as vendas destes rincões, trocando objetos, enquanto deixa a mulher e um par de filhos aos próprios cuidados. Em qualquer parte que vá, o acompanha uma forte matilha de cães ferozes que ofazem deveras temido. Menos de uma dúzia nunca o cercam. Mas, justiça lhe seja feita: tem os bichos na mão, atendem prontamente a seu assovio e temem mais sua voz que seu chicote. Conhecendo ele, como a palma da mão, toda a selva ao longe e perto, valiam-se dele os negociantes e ainda se valem para mostrar seus artigos aos silvícolas do interior. Isso fazia de muito bom gosto, pois os negociantes em paga lhe davam pinga. Outras vezes servia de guia para os compradores e agenciadores de terras a quem apontava os melhores chãos. Nada perdeu da natureza selvagem e ainda hoje é como há anos um amigo da onça, um cabra valente e destemido e, por isso, evitado quanto possivel. [...]. Não quer saber, porém, que o chamem de Bugre. De modo nenhum. Mas Luís Antônio. O epiteto que os brancos lhe deram é um sinonimo de desprezo, uma injúria, uma desonra. (GANSWEIDT, 1946, p. 41).

Mas afinal do que se trata a expressão "bugre" e porque Luis a consideraria depreciativa? Ora, inicialmente porque é assim que o chamam os que o colocaram nessa situação ambígua de pertencimento a dois mundos (do índio e do imigrante), forçando-o a criação de uma identidade híbrida ao extremo, retirando-o do mundo dos seus.

A expressão bugre parece ter sido usada de forma mais geral para denominar os indivíduos ou grupos de indígenas "[...] não dispostos aos projetos de catequização e, posteriormente, de civilização implementados pela administração da colônia e do império.” (DORNELLES, 2011, p. 271) Também há a hipótese de que tenha sido um termo derivado da expressão pucri, grito de guerra dos índios coroados, podendo então servir para diferenciar esse grupo dos nativos guaranis. Essas seriam conceituações mais generalizantes, sendo que no contexto da obra da qual tratamos aqui pode-se utilizar essa denominação como algo mais particular como “ [...] vinculado a indivíduos com experiências específicas, como a vivenciada por Luís Bugre.” (DORNELLES, 2011, p. 272) Mas que experiências específicas seriam essas? Terem sido submetidos de forma forçada a transitar em dois universos distintos, passando a assumir a função de intermediários entre esses contextos culturais: "[...] aprenderam a ser um pouco do "outro", de modo a negociar suas identidades em busca de vantagens naquela situação.” (DORNELLES, 2011, p. 273).

De forma bastante resumida é preciso trazer para este texto qual o enredo contado por Ganweidt em "As vítimas do bugre". Trata-se de uma narrativa sobre fatos decorridos de um sequestro de uma mãe e seus dois filhos, Valfrida Versteg, seu filho Jacó, na época com 14 anos e a filha Lucila com 12 anos. Na noite do sequestro o pai da família estava ausente, visitando amigos em São Sebastião do Caí. No que ele saiu de casa teria Luis Bugre avisado a Sra Valfrida para que colocasse uma toalha branca em seu telhado, para que os índios não lhes fizessem mal. Esse era o sinal combinado para a identificação da casa a ser atacada pelos nativos. O rancho foi atacado, roubado e as pessoas levadas junto mata adentro. Ao retornar, Lamberto, o pai, 
encontra sua propriedade naquele estado e reúnem-se duas expedições para a busca dos prisioneiros, a segunda com ajuda de cães e agentes oficiais, mas nenhuma teve sucesso.

Valfrida e os filhos são obrigados a seguir com os caingangues, com pés machucados, cansaço extremo até chegar ao nordeste do estado, região de circulação dos nativos. Os brancos teriam sido colocados sob os cuidados de uma índia idosa que os tratava bem. Jacó, o menino aos poucos ia sendo introduzido na lida dos afazeres dos homens e da mesma forma as mulheres imigrantes. Teriam ficado entre os indígenas por cerca de dois anos, enquanto isso, Lamberto vendeu a propriedade e foi embora sem deixar pistas. Ao final daqueles dois anos o grupo entrou em guerra contra os Coroados no Norte, sendo que depois desse confronto a índia cuidadora veio a falecer, deixando sem proteção os alemães. Não se sabe ao certo o que teria acontecido com Valfrida e Lucila, pois ao que tudo indica elas desapareceram. Jacó, percebendo que as coisas não andavam muito boas para o seu lado planeja sua fuga, que ocorreu logo ao final de uma festa. Jacó foi acolhido em uma estância e encontrava-se nos Campos de Cima da Serra. Ficou sabendo do que Lamberto havia feito e decidiu ir a São Leopoldo tentar encontras pistas do paradeiro do pai. Encontrou-o seis meses depois trabalhando no porto do Rio dos Sinos como estivador, não muito tempo depois Lamberto faleceu. Jacó voltou a São Vendelino, cidade onde casou-se com Carolina Weirich, tendo com ela treze filhos. (DORNELLES, 2011)

\section{Gansweidt e o "outro”}

Matias José Gansweidt nasceu em 1874 em Birgelen, Alemanha, estudou na Holanda e Bélgica, vindo terminar sua formação no Seminário Episcopal de Porto
Alegre. Foi ordenado sacerdote em 1903 e foi pároco em São Lourenço do Sul, São Gabriel, Bom Jardim, Venâncio Aires e Poço das Antas. Escrevia poemas e contos, além de dois livros: "Chico Monge e seu Bando"; e "As Vítimas do Bugre".

Passamos agora a buscar na obra "As vítimas do Bugre" alguns recortes que podem ilustrar o imaginário da época, representando principalmente as formas dos imigrantes perceberem a si mesmos e aos outros, neste caso os indígenas. "[...] (Gansweidt) ao escolher a terceira pessoa como perspectiva narrativa de seu romance, pode atribuir sentimentos a personagens aos quais não teve acesso e, assim, fazê-los representativos das impressões dos colonos alemães em geral." (DORNELLES, 2011, p. 273).

A respeito dos imigrantes alemães o discurso que predomina é o do trabalho, da honestidade, da coragem em assumir a empreitada da colonização com esparsos recursos e as condições mais contrárias. Em trecho inicial da obra, na viagem em busca do lote correto a ser destinado aos Versteg a família pousa e se alimenta na propriedade do Sr. José dos Santos que se despede deles com a seguinte frase: “- Sejam sempre bemvindos os colonos alemães, que são homens trabalhadores, honestos e hão de construir a grandeza da nossa terra." (GANSWEIDT, 1946, p. 17).

Já em relação aos indígenas a perspectiva é bastante diferente, do início ao final da narrativa Gansweidt refere-se aos nativos como selvagens, silvícolas, cruéis, ou ainda "demônios". "Fugiram tropeçando, caindo, derrubando-se mutuamente qual bando de demônios acossados por água benta." (GANSWEIDT, 1946, p. 39). Essa é apenas uma passagem para exemplificar a caracterização desse grupo humano, pois o termo selvagem ${ }^{10}$, aparece inúmeras vezes, representan-

\footnotetext{
${ }^{10}$ Vale lembrar que a ideia de barbarismo não é exclusiva dos povos gregos da Antiguidade Clássica, constituindo-se num dos fundamentos de muitas culturas pelo mundo, como no caso da China Antiga, por exemplo
} 
do o indígena como um assassino cruel, selvagem irracional por natureza. "A natureza selvagem dos índios não lhes consente olvidar uma afronta ou deixar de exercer uma represália." (GANSWEIDT, 1946, p. 243). Herdada do gregos a concepção do outro acaba por colocar em lados opostos a civilização e a selvageria, logo quem não é civilizado no sentido greco-romano, deve ser "selvagem". "No pensamento grego a noção de selvagem denotava tanto aqueles que não falavam grego, o que chegava a ser equivalente a não possuir linguagem, quanto significava crueldade." (WOORTMANN, 2000, p. 18). Reproduz ainda a questão da cidade como espaço da civilização e a floresta (fora da cidade) como o local da selvageria, diretamente relacionada ao habitat do indígena, quanto mais se o mesmo oferece resistência a catequização indicando "querer" permanecer na barbárie.

É na construção conceitual do outro que se afirma a própria identidade, é percebendo o outro que sei quem eu não sou e portanto quem sou passa a ser tudo o que o outro não é, em um modelo de inversão de valores, de oposição, de afirmação de diferenças, o que não significa necessariamente a compreensão delas. "É um jogo de alteridades na difícil relação com esse Outro radicalmente exótico, tão problemático e necessário quanto o selvagem mítico para a afirmação de uma identidade grega." (WOORTMANN, 2000, p. 19). Ainda, de acordo com a autora "Vale ressaltar que canibalismo, gigantismo, desconhecimento da agricultura, comer cru etc. permaneceram atributos do selvagem até o encontro com os ameríndios." (WOORTMANN, 2000, p. 20).

Outro atributo do selvagem seria o nomadismo, que realmente era uma característica do indígena referido na história, sabe-se que esses grupos se deslocavam em grandes espaços do Rio Grande do Sul.
"O povo selvagem e nômade que ainda continua sendo ameaça negra para a Colônia, pertence a tribo dos guianeses. Não são outros que os atuais caingangues. Variam suas denominações de região para região: coroados ou bugres no Rio Grande do Sul, camés em S. Paulo, chorrés no Paraná e socrés em Santa Catarina." (GANSWEIDT, 1946, p. 7).

Assim é feita a construção do indígena em oposição ao civilizado, no caso personificado na imagem do imigrante alemão. O alemão é tudo o que o índio não é: civilizado, trabalhador, organizado, honesto, veio para trazer o progresso para a região. Já o índio é tido como preguiçoso, ladrão, selvagem, cruel, assassino. Esse discurso prevalece mesmo sobre as falas de Valfrida que na narrativa em vários momentos surpreende-se pela "boa índole" dos coroados nos cuidados com eles “[...] convencendo-se mais e mais de que os bugres, apesar de rudes e cruéis, sabem ter bons sentimentos e compaixão, o que muito a consola." (GANSWEIDT, 1946, p. 89).

Tzvetan Todorov afirma a existência de no mínimo três eixos nos quais pode ser compreendida a questão da alteridade.

\begin{abstract}
"Primeiramente, um julgamento de valor (um plano axiológico): o outro é bom ou mau, gosto dele ou não gosto dele, ou, como se dizia na época, me é igual ou me é inferior [...]. Há, em segundo lugar, a ação de aproximação ou de distanciamento em relação ao outro (um plano praxiológico): adoto os valores do outro, identifico-me a ele; ou então assimilo o outro, impondo-lhe minha própria imagem; entre a submissão ao outro e a submissão do outro há ainda um terceiro termo, que é a neutralidade, ou indiferença. Em terceiro lugar, conheço ou ignoro a identidade do outro (seria o plano epistêmico); [...]" (TODOROV, 1999, p. 223)
\end{abstract}

Fica clara que a perspectiva da narrativa de Gansweidt ficou apenas no plano axiológico, sem estabelecer nenhum tipo de aproximação com o grupo indígena, tanto que toda a história é fundamentada nos rela- 
tos de Jacó Versteg e outros imigrantes, é através deles que se tem os conceitos do outro, do indígena. A narrativa transborda o olhar do imigrante sobre o nativo, sendo que devem ter ocorrido diversos ataques de imigrantes aos indígenas, mas a escolha foi por relatar um ataque de nativos aos imigrantes, deixando bem claro o total desinteresse em dar voz aos caingangues.

"As vítimas do Bugre" foi uma narrativa de grande força na região de imigração alemã, sendo leitura bastante disseminada, principalmente na sua versão em alemão. "Se mesmo quase vinte anos após a primeira identificação da potencialidade da narrativa, a mesma permaneceu merecendo o estatuto de poder tornarse um livro, pode-se acreditar que essa história possui grande significado para a comunidade de onde foi capaz de emergir e de permanecer viva." (DORNELLES, 2011, p. 248)

É, acima de tudo, uma narrativa que reflete a forma de pensar de uma época, representando o seu imaginário acerca dos fatos ocorridos e mais, reforçando-os para as novas gerações que virão depois e que não foram contemporâneas ao ocorrido. Narrativas como essa tem grande poder de "criar verdades". Essa "verdade" reforçou o conceitual de selvagem do indíge- na e contribuiu como recurso narrativo voltado para a construção de uma identidade teuta no Rio Grande do Sul.

\section{Conclusão}

A difusão dessas representações contribuiu para a construção de uma memória que legitimou os alemães como agentes civilizadores, que se opunham aos indígenas - cuja imagem esteve associada ao universo incivilizado, hostil e barbarizado. Essas imagens sobre os indígenas, inscritas na produção cultural desde o período colonial, são atualizadas e são redimensionadas dentro do contexto da imigração alemã, na medida em que se procurava legitimar a ação civilizadora dos alemães no sul do Brasil.

Tomados como representantes de uma intelectualidade teuto-sul-rio-grandense, os autores analisados defenderam, antes de tudo, os sentimentos da germanidade, que se manifestava pelo orgulho étnico e pela herança trazida da pátria-mãe, a Alemanha. As imagens difundidas sobre o espaço conquistado e sobre seus primeiros habitantes serviu, sem dúvida, de ponto de legitimação para a afirmação da identidade étnica dos alemães no sul do Brasil. 


\section{Referências bibliográficas}

BOHNEN, Aloysio; ULLMANN, Reinholdo A. A atividade dos jesuitas de São Leopoldo (1944-1989). São Leopoldo: UNISINOS, 1989.

BOURDIEU, Pierre. A economia das trocas lingüisticas. São Paulo: Edusp, 1998.

BOURDEU, Pierre. O poder simbólico. 4 ed. Rio de Janeiro: Bertrand Brasil, 2001.

BURKE, Peter. Testemunha ocular. História e imagem. Bauru: EDUSC, 2004.

BURKE, Peter. Uma História Social do Conhecimento: de Gutenberg a Diderot. Rio de Janeiro: Jorge Zahar, 2003.

CANDAU, J. Memória e identidade. São Paulo: Contexto, 2012.

CARDOSO, Ciro F. História e textualidade. In: CARDOSO, Ciro F.; VAINFAS, Ronaldo. Novos Domínios da História. Rio de Janeiro: Elsevier, 2012. p. 225-242.

CHARTIER. Roger. À beira da falésia: a história entre certezas e inquietude. Porto Alegre: UFRGS, 2002.

DECCA, Edgar Salvadori de. Literatura em Ruínas ou as Ruínas na Literatura? In: BRESCIANI, Stella e NAXARA, Márcia (orgs). Memória e (res)sentimento: indagações sobre uma questão sensível. Campinas: UNICAMP, 2004.

DICKIE, Maria Amélia Schmidt. Afetos e Circunstâncias. Um Estudo Sobre os Mucker e Seu Tempo. São Paulo, 1996. Tese de Doutorado em Antropologia Social. USP.

DOMINGUES, Moacyr. A nova face dos Muckers. São Leopoldo: Rotermund, 1977.

DORNELLES, Soraia S. A história em As vítimas do bugre, ou como tornar-se bugre na História. In Revista Anos 90, Porto Alegre: UFRGS, v. 18, n. 34, p. 245-278, dez. 2011. Disponível em: <http://seer.ufrgs.br/index.php/ anos90/article/view/24028/19729>. Acesso em: 4 nov. 2015.

DREHER, Martin N. 190 anos de imigração alemã no Rio Grande do Sul: esquecimentos e lembranças. São Leopoldo: Oikos, 2014.

FERREIRA, Antonio Celso. Heróis e vanguardas, romance e história: os intelectuais modernistas de São Paulo e a construção de uma identidade regional. In: PESAVENTO, Sandra J. (org). Escrita, linguagem, objetos: leituras de História Cultural. Bauru: EDUSC, 2004.

GANSWEIDT, Matias José. As vítimas do Bugre. Porto Alegre: Selbach, 1946.

HALBWACHS, M. A memória coletiva. São Paulo: Centauro, 2004.

HARTOG, François. Regimes de historicidade: presentismo e experiências do tempo. São Paulo: Autêntica, 2014.

LIMA, Henrique E. Micro-história. In: CARDOSO, Ciro F.; VAINFAS, Ronaldo. Novos Domínios da História. Rio de Janeiro: Elsevier, 2012. p. 207-223.

POLLACK, Michael. Memória, esquecimento, silêncio. Estudos Históricos, Rio de Janeiro, v. 2. n. 3, 1989.

POUTIGNAT, P; STREITFF-FENART, J. Teorias da Etnicidade seguido de Grupos Étnicos e suas Fronteiras de Frederik Barth. São Paulo: Editora da UNESP, 1998.

SCHUPP, Ambrósio. Os Muckers. 3. ed. Porto Alegre: Selbach e Mayer, s/d.

SEIXAS, Jacy Alves de. Percursos de memórias em terras de história: problemas atuais. In: BRESCIANI, Stella e NAXARA, Márcia (Org.). Memória e (res)sentimento: indagações sobre uma questão sensível. Campinas: UNICAMP, 2004.

SELIGMANN-SILVA, Márcio. O local da diferença. Ensaios sobre memória, arte, literatura e tradução. São Paulo: Editora 34, 2005. p. 76.

SEYFERTH, Giralda. Memória coletiva, identidade e colonização: representações da diferença cultural no Sul do Brasil. MÉTIS: história \& cultura. v. 11, n. 22, jul./dez. 2012. p. 13-39. 
SEYFERTH, G. A dimensão cultural da imigração. Revista Brasileira de Ciências Sociais. vol. 26, n. 77. p. 47-62, 2011.

SILVA, Marcio A. B. da. Positivismo e colonização no Rio Grande do Sul da Primeira República (1889-1930). In: TEDESCO, João C.; NEUMANN, Rosane M. (orgs). Colonos, colônias e colonizadoras: aspectos da territorialização agrária no sul do Brasil. vol. 3. Porto Alegre: Letra\&Vida, 2013. p. 117-143.

TODOROV, Tzvetan. A conquista da América: a questão do outro. São Paulo: Martins Fontes, 1999.

VON KOSERITZ, Carlos. A Fraude Mucker na Colônia Alemã. Uma contribuição para a história da cultura da germanidade daqui. Koseritz Kalender. (Tradução de Martin N. Dreher).

VON KOSERITZ, Carlos. Marpingen und der Ferrabraz. In: PETRY, Leopoldo. O episódio do Ferrabraz: os mucker. 2. ed. São Leopoldo: Rotermund, 1966. p. 170-173.

WOODWAR, K. Identidade e diferença: uma introdução teórica e conceitual. In: SILVA, T. T. da (org). Identidade e diferença: a perspectiva dos Estudos Culturais. 14 ed. Petrópolis: Vozes, 2014. p. 7-72.

WOORTMANN, Klaas. O selvagem e a história. Heródoto e a questão do outro. Rev. Antropol., São Paulo, v. 43, n. 1, p. 13-59, 2000 . Disponível em: $<$ http://www.scielo.br/scielo.php?script=sci_arttext\&pid=S003477012000000100002\&lng=en\&nrm=iso $>$. Acesso em: 5 nov. 2015. <http://dx.doi.org/10.1590/S0034$77012000000100002>$. 